\title{
Role of Membrane Performance Enhancer in Membrane Bioreactor: A Comparison with other Submerged Membrane Hybrid Systems
}

\author{
W. S. Guo ${ }^{1}$, S. Vigneswaran ${ }^{1 *}$, H. H. Ngo ${ }^{1}$, J. Kandasamy ${ }^{1}$ and S Yoon ${ }^{2}$ \\ 1 Faculty of Engineering, University of Technology, Sydney, P.O. Box 123, Broadway, NSW 2007, Australia. \\ 2 Nalco Company, 1601 West Diehl Rd., Naperville, 11 60563-1198, USA, \\ *Correspondence author, tel: +61-2-9514-2641,fax: +61-2-9514-2633, E-mail: S.Vigneswaran@uts.edu.au
}

\begin{abstract}
Among the membrane processes, membrane bioreactor (MBR) technologies are becoming an innovative and promising option for wastewater treatment and reuse. In this study the performance of the SMBR was studied with an addition of MPE50 was compared against sponge submerged membrane bioreactor (SMBR) and SMABR in terms of TOC removal, COD removal, ammonium nitrogen $\left(\mathrm{NH}_{4}-\mathrm{H}\right)$ removal, orthophosphate $\left(\mathrm{PO}_{4}-\mathrm{P}\right)$ removal, transmembrane pressure (TMP) and oxygen uptake rate. SMBR with MPE50 addition significantly improved the sustainable flux and reduced the membrane fouling. The improvement was better than even the sponge SMBR system. SMBR with MPE50 achieved a high DOC and COD removal efficiency and $\mathrm{NH}_{4}-\mathrm{N}$ removal. $\mathrm{PO}_{4^{-}}$ $P$ removal concentration of $62 \%$ initially which increased with time to over $99 \%$ after 7 days operation. In terms of phosphorus removal the sponge SMBR system performed better. OUR measurements showed that there was more microbial activity in the SMBR with MPE50 system
\end{abstract}

KEYWORDS: Submerged membrane bioreactor; critical flux; transmembrane pressure, membrane performance enhancer

\section{INTRODUCTION}

The consumption of limited waste resources together with the need to comply with ever more stringent water quality standards, and the need to reuse of water are the main impetus for the development of membrane technologies. Among the membrane processes, membrane bioreactor (MBR) technologies are becoming an innovative and promising option for wastewater treatment and reuse. MBR integrates a suspended growth bioreactor and filtration through a porous membrane, which leads to the total retention of biomass (high microbial concentration) and improved biological reactor operation (high sludge ages) in the bioreactor [1].

The advantages of MBR over conventional activated sludge (AS) are well documented, which include superior organics removal, enhanced nutrient removal stability, lower sludge production, smaller footprint, effluent disinfection and high loading grate capabilities [1]. In the design of MBR systems, the submerged membrane bioreactor (SMBR) can significantly reduce power consumption compared to an external loop mode.

Guo et al. [2] compared the performance of submerged membrane bioreactor (SMBR) and submerged membrane adsorption bioreactor (SMABR) over a period of 20 days at a hydraulic retention time (HRT) of 3.1 hours. The effects of powder activated carbon (PAC) on critical flux and membrane fouling were also investigated. The SMABR exhibited better results in terms of mixed liquor suspended solids (MLSS) growth, TOC removal (over 96\%), COD removal (over 95\%), transmembrane pressure (TMP) and oxygen uptake rate. Nearly 100\% of total coliforms were removed in both systems. The addition of PAC could maintain the critical flux at a lower TMP value $(7.5 \mathrm{kPa})$, although the critical flux value was the same as that for the SMBR.

Guo et al. [3] compared the performance of two different membrane bioreactor (MBR) systems, 
namely SMBR alone and sponge-SMBR system, in terms of critical flux. The addition of $10 \%$ volume fraction of sponge in the bioreactor increased the sustainable flux of SMBR system by 2 times.

A newly developed membrane performance enhancer (MPE) was found to significantly prevent membrane fouling in a membrane bioreactor (MBR) process [4]. Experiments conducted using 50$1,000 \mathrm{mg} / \mathrm{l}$ of MPE reduced polysaccharide levels by half, reduced significantly the membrane fouling and increased the intervals between membrane cleanings. Depending on MPE dosages and experimental conditions, transmembrane pressure (TMP) increase was suppressed for 20-30 days, while baseline TMP surged within a few days. In this study the performance of the SMBR was studied with an addition of MPE and compared against sponge SMBR and SMABR in terms of TOC removal, COD removal, ammonium nitrogen $\left(\mathrm{NH}_{4}-\mathrm{H}\right)$ removal, orthophosphate $\left(\mathrm{PO}_{4}-\mathrm{P}\right)$ removal, transmembrane pressure (TMP) and oxygen uptake rate.

\section{EXPERIMENTAL}

\section{Wastewater}

The experiments were conducted using a synthetic wastewater to avoid any fluctuation in the feed concentration and provide a continuous source of completely biodegradable organic pollutants. The synthetic wastewater has total organic carbon (TOC) of 120-130 mg/L and COD of 320-350 mg/L (COD: $\mathrm{N}: \mathrm{P}=100: 5: 1$ ). The composition of synthetic waster is given in Table 1, [5]. $\mathrm{NaHCO}_{3}$ or $\mathrm{H}_{2} \mathrm{SO}_{4}$ were added to the wastewater to maintain a constant $\mathrm{pH}$ around 7 .

The configuration of the SMBR is shown in figure 1. The unit was filled with sludge and acclimatized to synthetic wastewater for 12 days. In the SMBR system, a predetermined amount of MPE50 (500 mg/L) was added into the reactor at the start of the experiment and on a daily basis an additional $80 \mathrm{mg} / \mathrm{l}$ was added. A polyethylene hollow fiber membrane module was used with the pore size of $0.1 \mu \mathrm{m}$ and surface area of $0.195 \mathrm{~m}^{2}$. For physical cleaning, filtrate backwash was used every 1 hour for 1 min duration at a backwash rate of $30 \mathrm{~L} / \mathrm{m}^{2} . h$.

Based on our past experience of Nalco the optimum dosage for municipal WW was $100 \mathrm{mg} / \mathrm{L}$ for every 3g/L MLSS with a variation of $+/-50 \%$. Since the MLSS of the sludge used in this study was $10 \mathrm{~g} / \mathrm{L}$ the optimum dosage is most likely to be around $333 \mathrm{ppm}$ with a possible range of 170-500 $\mathrm{ppm}$. This is the reason why we used a dose of $500 \mathrm{ppm} / \mathrm{L}$ on the first day followed by a daily dose of $80 \mathrm{ppm} / \mathrm{L}$.

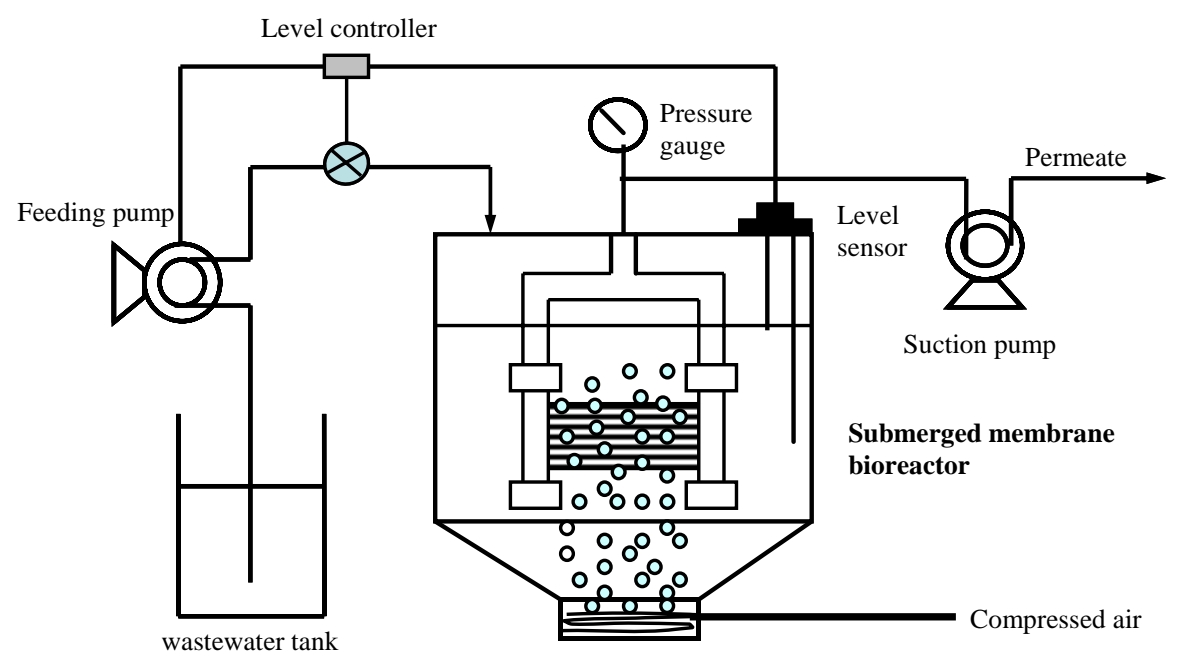

Figure 1 Experimental set-up of SMBR 
Table 1 Constituents of the Synthetic Wastewater

\begin{tabular}{lcc}
\hline Compounds & $\begin{array}{c}\text { Molecular weight } \\
(\mathrm{g} / \mathrm{mol})\end{array}$ & $\begin{array}{c}\text { Concentration } \\
(\mathrm{mg} / \mathrm{L})\end{array}$ \\
\hline Organics and nutrients & 180.0 & 280 \\
$\quad$ Glucose $\left(\mathrm{C}_{6} \mathrm{H}_{12} \mathrm{O}_{6}\right)$ & 132.1 & 72 \\
Ammonium sulfate $\left(\left(\mathrm{NH}_{4}\right)_{3} \mathrm{SO}_{4}\right)$ & 136.1 & 13.2 \\
Potassium phosphate $\left(\mathrm{KH}_{2} \mathrm{PO}_{4}\right)$ & & \\
& & \\
Trace nutrients & 147.0 & 0.368 \\
Calcium chloride $\left(\mathrm{CaCl}_{2} \cdot 2 \mathrm{H}_{2} \mathrm{O}\right)$ & 246.5 & 5.07 \\
Magnesium sulfate $\left(\mathrm{MgSO}_{4} \cdot 7 \mathrm{H}_{2} \mathrm{O}\right)$ & 197.9 & 0.275 \\
Manganese chloride $\left(\mathrm{MnCl}_{2} \cdot 4 \mathrm{H}_{2} \mathrm{O}\right)$ & 287.5 & 0.44 \\
Zinc sulfate $\left(\mathrm{ZnSO} \cdot 7 \mathrm{H}_{2} \mathrm{O}\right)$ & 162.2 & 1.45 \\
Ferric chloride anhydrous $\left(\mathrm{FeCl}_{3}\right)$ & 249.7 & 0.391 \\
Cupric sulfate $\left(\mathrm{CuSO} \cdot 5 \mathrm{H}_{2} \mathrm{O}\right)$ & 237.9 & 0.42 \\
Cobalt chloride $\left(\mathrm{CoCl}_{2} \cdot 6 \mathrm{H}_{2} \mathrm{O}\right)$ & 242.0 & 1.26 \\
Sodium molybdate dihydrate $\left(\mathrm{Na}_{2} \mathrm{MoO}_{4} \cdot 2 \mathrm{H}_{2} \mathrm{O}\right)$ & & 30 \\
Yeast extract & & \\
\hline
\end{tabular}

\section{RESULTS AND DISCUSSION}

Sustainable flux of MBR system

The critical flux hypothesis for microfiltration (MF) assumes that on start-up there exists a flux below which a decline of flux with time does not occur and above which fouling is observed [6]. Critical fluxes can be determined experimentally from flux-transmembrane pressure (TMP) profiles at constant fluxes or pressures, particle mass balances [7] or direct visual observations of deposits on membranes [8]. Among these, the hydraulic methods are the most popular. The simplest variant of hydraulic methods involves finding the point where the obtained flux-TMP profile became nonlinear. The stepwise increase of constant flux (or TMP) is technically similar but also includes the 'in-process' verification of the result. These procedures are well documented and discussed in the literature [9].

In these experiments, we briefly compared the stepwise increase of both TMP and flux, and found the latter method to be more convenient and reproducible. These screening tests revealed the practicality of using 40 min TMP monitoring intervals. Accordingly, the critical flux is the flux below which there is no increase in resistance to permeation (i.e. the TMP remains constant with time). In the case of SMBR, 'sub-critical' flux operation does not appear to be feasible and the challenge is to determine the 'sustainable flux', where the rise in transmembrane pressure (TMP) is tolerable before rapid fouling and increase of TMP occurs [10].

Critical flux experiments were carried out at the end of long term SMBR experiments. The membrane was physically cleaned by backwashing and the cake layer formed by activated sludge was brushed off before starting the critical flux experiment. During every 40 minutes flux-step, 1 minute backwash was provided at a backwash rate of $30 \mathrm{~L} / \mathrm{m}^{2} . h$ using membrane filtrate. The purpose of backwash was mainly to minimise the rise in TMP due to reversible fouling during each experimental flux-step, which could lead to TMP development during the descending flux cycle compared to the ascending flux cycle. 
As can be seen in Figure 2, MPE50 could significantly reduce the membrane fouling and enhance sustainable flux from $25 \mathrm{~L} / \mathrm{m}^{2}$.h to $60 \mathrm{~L} / \mathrm{m}^{2}$.h with the addition of MPE50. The performance of the SMBR with MPE50 was even superior to the sponge-MBR system, Table 2. Table 2 presents the critical flux of different MBR systems studied. It should be noted that the comparison of different systems were made under similar biological conditions and stages.

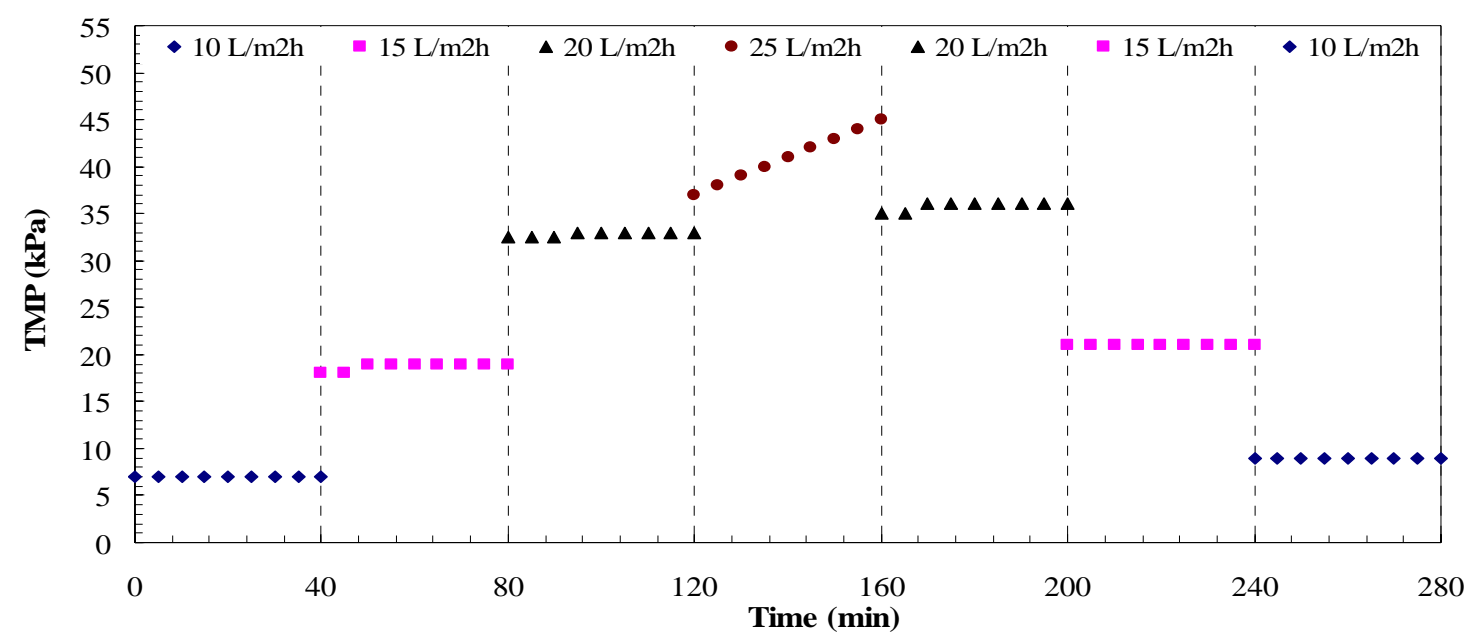

(a) SMBR only

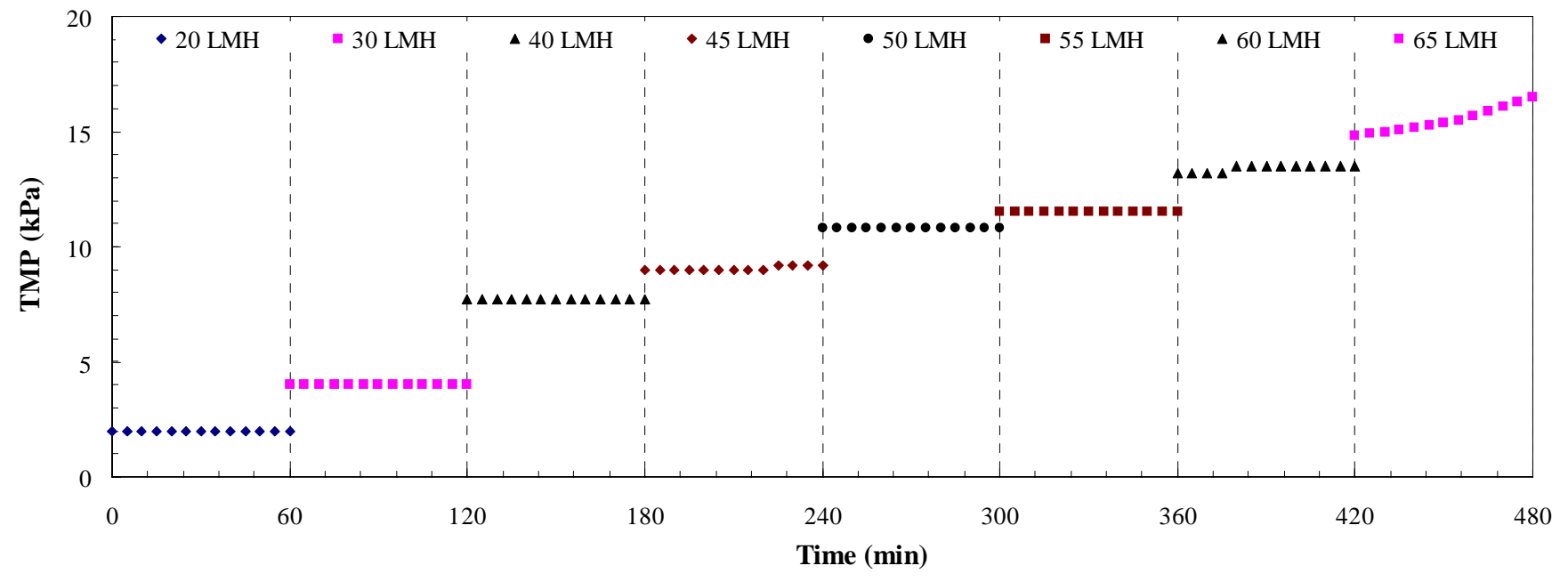

(b) SMBR with MPE50, $500 \mathrm{mg} / \mathrm{L}$ initially and $80 \mathrm{mg} / \mathrm{l}$ once per day

Figure 2. Constant filtration fluxes versus TMP of SMBR. (initial MLSS = $10 \mathrm{~g} / \mathrm{L}$; air flow rate $=9$ $\mathrm{L} / \mathrm{min})$

Table 2 Sustainable flux of SMBR and SMABR systems.

\begin{tabular}{|c|c|}
\hline System & Sustainable flux $\left(\mathrm{L} / \mathrm{m}^{2} . \mathrm{h}\right)$ \\
\hline SMBR & 20 \\
\hline SMABR & 20 \\
\hline SMBR with 10\% sponge volume & 50 \\
\hline SMBR with MPE50 & 60 \\
\hline
\end{tabular}




\section{DOC and COD removal}

The SMBR system with MPE50 was operated at a sludge concentration (in terms MLSS concentration) of $10 \mathrm{~g} / \mathrm{L}$. The permeate flux was kept constant at $30 \mathrm{~L} / \mathrm{m}^{2} . h$ with effective SMBR volume of 6 L. Figure 3 show the DOC and COD removal efficiencies during 7 days of operation. The results indicated that SMBR system achieved excellent DOC and COD removal efficiencies (over 95\%). Sponge SMBR system also achieved DOC removal efficiencies of over 95\% and COD removals of over $97 \%$, [3].

\section{$\mathrm{NH}_{4}-\mathrm{N}$ and $\mathrm{PO}_{4}-\mathrm{P}$ removal}

Nutrients removal in the SMBR was investigated in terms of ammonium nitrogen $\left(\mathrm{NH}_{4}-\mathrm{N}\right)$ and orthophosphate $\left(\mathrm{PO}_{4}-\mathrm{P}\right)$ removal. Over $95-98 \%$ of $\mathrm{NH}_{4}-\mathrm{N}$ was removed (Figure 3$)$. The removal of $\mathrm{PO}_{4}-\mathrm{P}$ increased with time. Initially the removal efficiency was $62 \%$ which increased with time to over $99 \%$ after 7 days operation, (Figure 3). For the sponge SMBR system, $\mathrm{NH}_{4}-\mathrm{N}$ removal was between $70-80 \%$. However, the $\mathrm{PO}_{4}-\mathrm{P}$ removal was higher (over 98\%) than the SMBR with MPE50.

\section{TMP development}

The measured variation of TMP values during the SMBR operation is shown in Figure 4. The results show that the TMP development was from 5 to $23 \mathrm{kPa}$ in seven days for the SMBR system with MPE50. By contrast, the TMP increase in the sponge SMBR was higher from 5 to $50 \mathrm{kPa}$ in seven days. The TMP development was the lowest for SMBR and SMABR systems (Table 3).

Table 3 TMP development for various MBR systems

\begin{tabular}{|c|c|}
\hline System & TMP Development $(\mathrm{kPa})$ \\
\hline SMBR & $8 \mathrm{kPa}$ in 20 days \\
\hline SMABR & $6 \mathrm{kPa}$ in 20 days \\
\hline SMBR with 10\% sponge volume & $45 \mathrm{kPa}$ in 7 days \\
\hline SMBR with MPE50 & $18 \mathrm{kPa}$ in 7 days \\
\hline
\end{tabular}

\section{Comparison of Oxygen uptake rate (OUR)}

OUR was measured in SMBR with MPE50 and compared with those of other hybrid configurations. YSI 5300 Biological Oxygen Monitor was used to measure oxygen uptake rate as it is a useful tool for measuring samples including respiration, oxidative activity, and cellular metabolism studies. The oxygen consumption measurement is achieved through use of an oxygen electrode with oxygen permeable Teflon membrane. Voltage generated from the reaction is proportional to the oxygen concentration of the sample and produces oxygen uptake or evolution curves in 2 to 15 minutes. During the acclimatization, the wastewater withdrawn from the aeration tank at different periods was monitored. Total organic carbon (TOC) of the influent and effluent was measured using the Analytikjena Multi N/C 2000. For measuring MLSS, three samples were taken each time and the average values were than calculated.

This data relates to the microbial activity at different periods of experiment. Figures $5 \mathrm{a}$ and $\mathrm{b}$ present the DO variation of the mixed liquor taken from the aeration tank of the SMBR alone and SMBR with MPE50. In SMBR system, the measured OUR value was lower during the first 3 days (55\% on the first day and $72 \%$ on the third day). Moreover, the OUR reached the equilibrium within 16 and 28 minutes with the mixed liquor taken after 1 and 3 days respectively. After that, the OUR of the SMBR system was over $94 \%$ and reached equilibrium within 14 minutes. The OUR in 
SMBR with MPE50 system had better performance from the initial stage of the experiment. The OUR was 98\% after 2 days of operation. Further the OUR value reached the equilibrium within 15 minuets and 6-7 minutes with the mixed liquor taken after 2 and 5 days respectively, which meant that there was more microbial activity in the SMBR with MPE50 system, (Figure 5b). The calculations showed that OUR increased from $34 \mathrm{mgO}_{2} / \mathrm{L} / \mathrm{hr}$ for $\mathrm{SMBR}$ to $66 \mathrm{mgO} / \mathrm{L} / \mathrm{hr}$ for SMBR-MPE50 which indicates 94\% increase with MPE50.

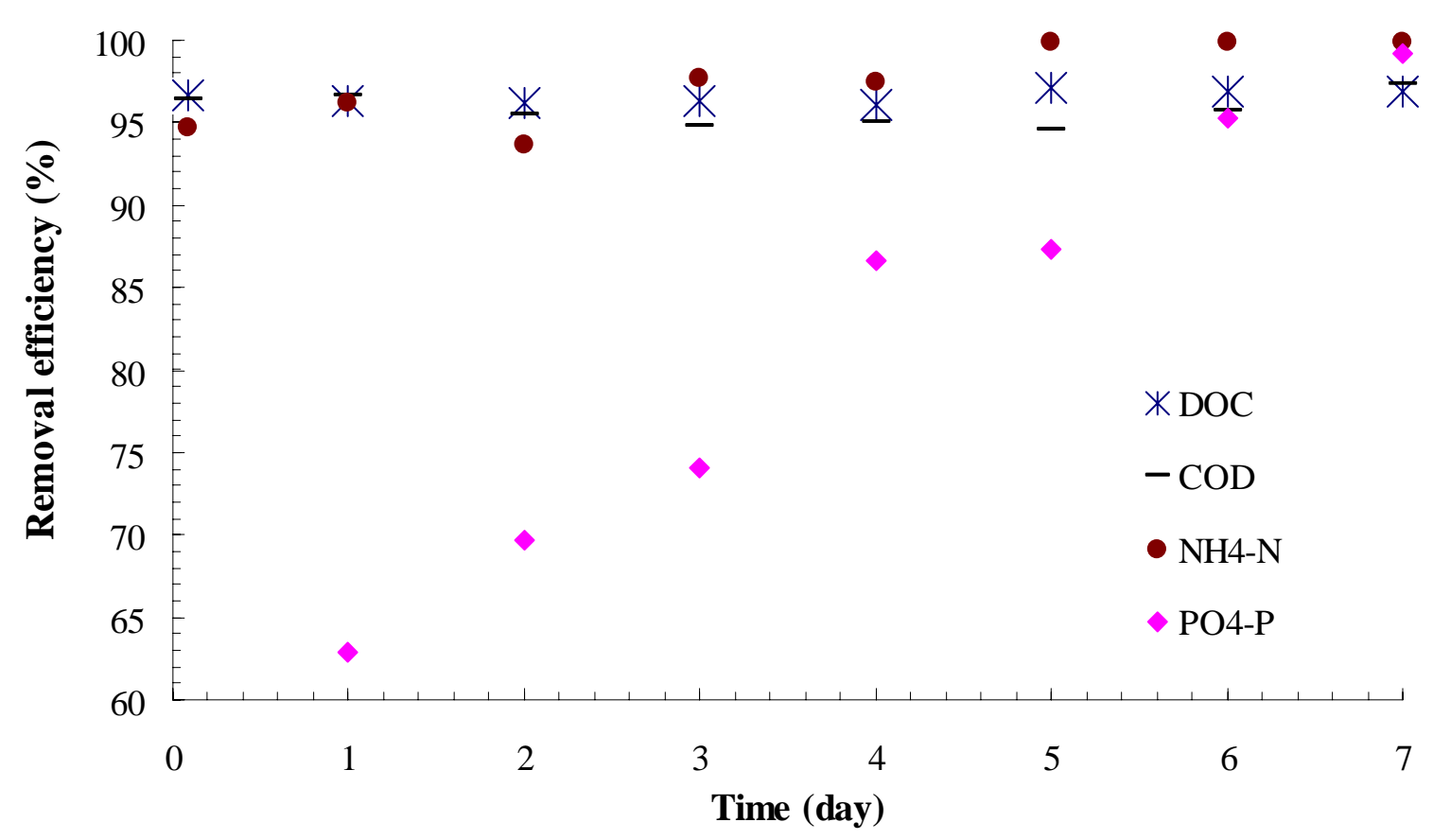

Figure 3. Removal efficiency profile of SMBR+MPE50 in $6 \mathrm{~L} \mathrm{tank}$, (filtration flux $=30 \mathrm{~L} / \mathrm{m}^{2} . \mathrm{h}$; MPE50 initial dose $=500 \mathrm{mg} / \mathrm{L}$ and daily addition of $80 \mathrm{mg} / \mathrm{L}$; backwash rate $=30 \mathrm{~L} / \mathrm{m}^{2} . \mathrm{h}$; backwash = 1 minute every 0.5 hour, daily addition of $300 \mathrm{~g}$ )

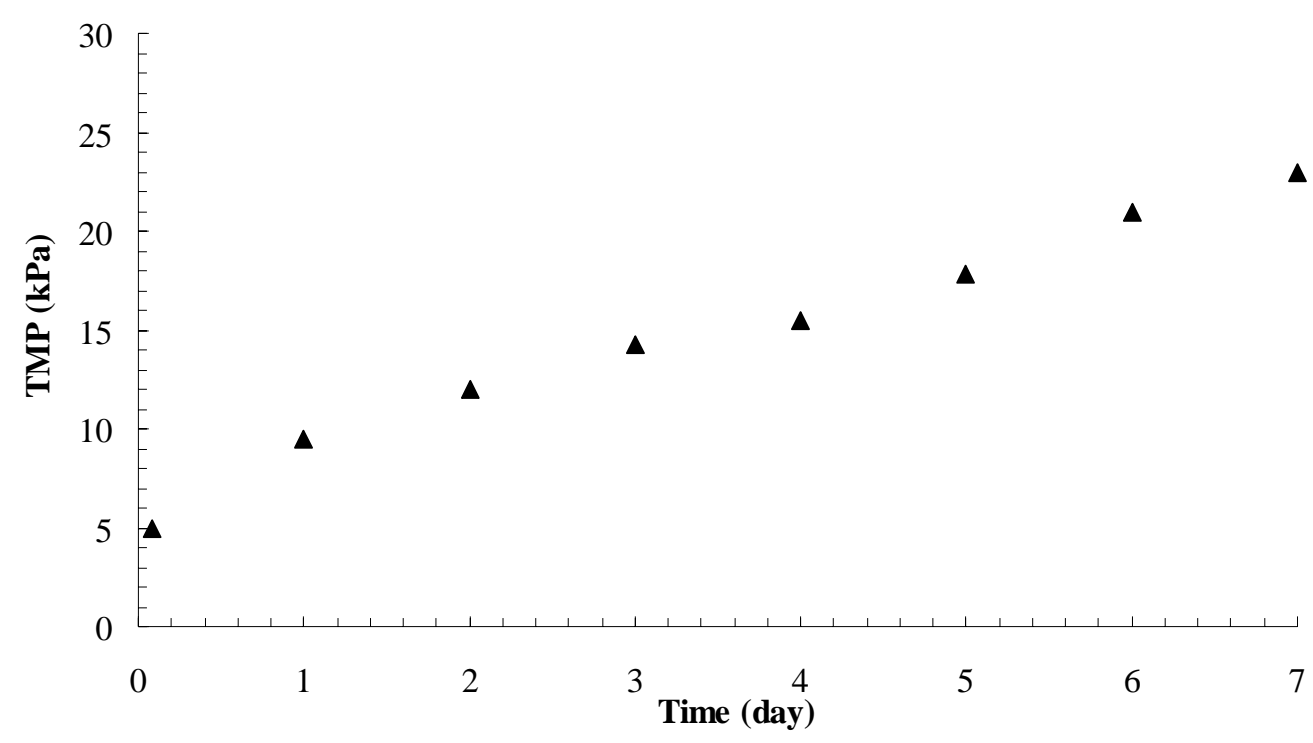

Figure 4. TMP efficiency profile of SMBR+MPE50 (MLSS $=10 \mathrm{~g} / \mathrm{L}$, filtration flux $=30 \mathrm{~L} / \mathrm{m}^{2} . \mathrm{h}$; MPE50 initial dose $=500 \mathrm{mg} / \mathrm{L}$ and daily addition of $80 \mathrm{mg} / \mathrm{L}$; backwash rate $=30 \mathrm{~L} / \mathrm{m}^{2} . \mathrm{h}$; backwash $=1$ minute every 0.5 hour) 


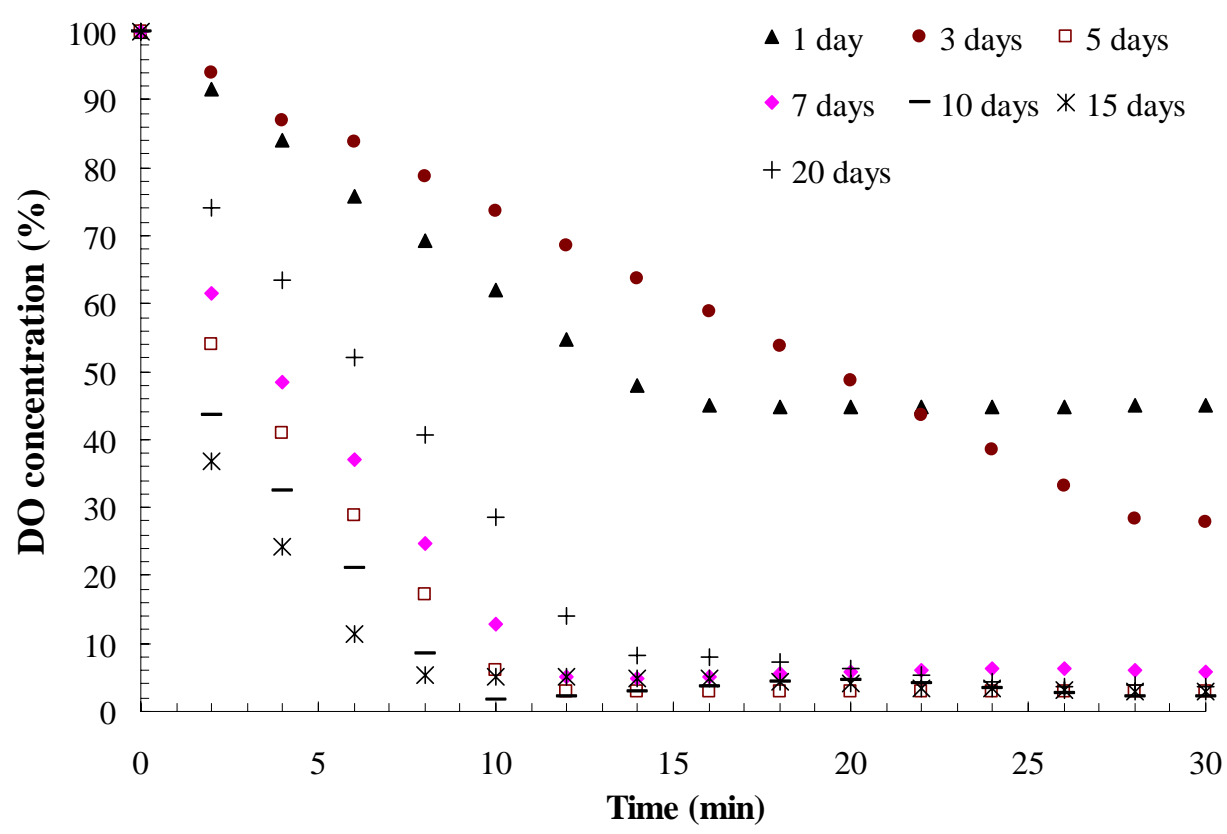

a) OUR variation of the mixed liquor in SMBR system

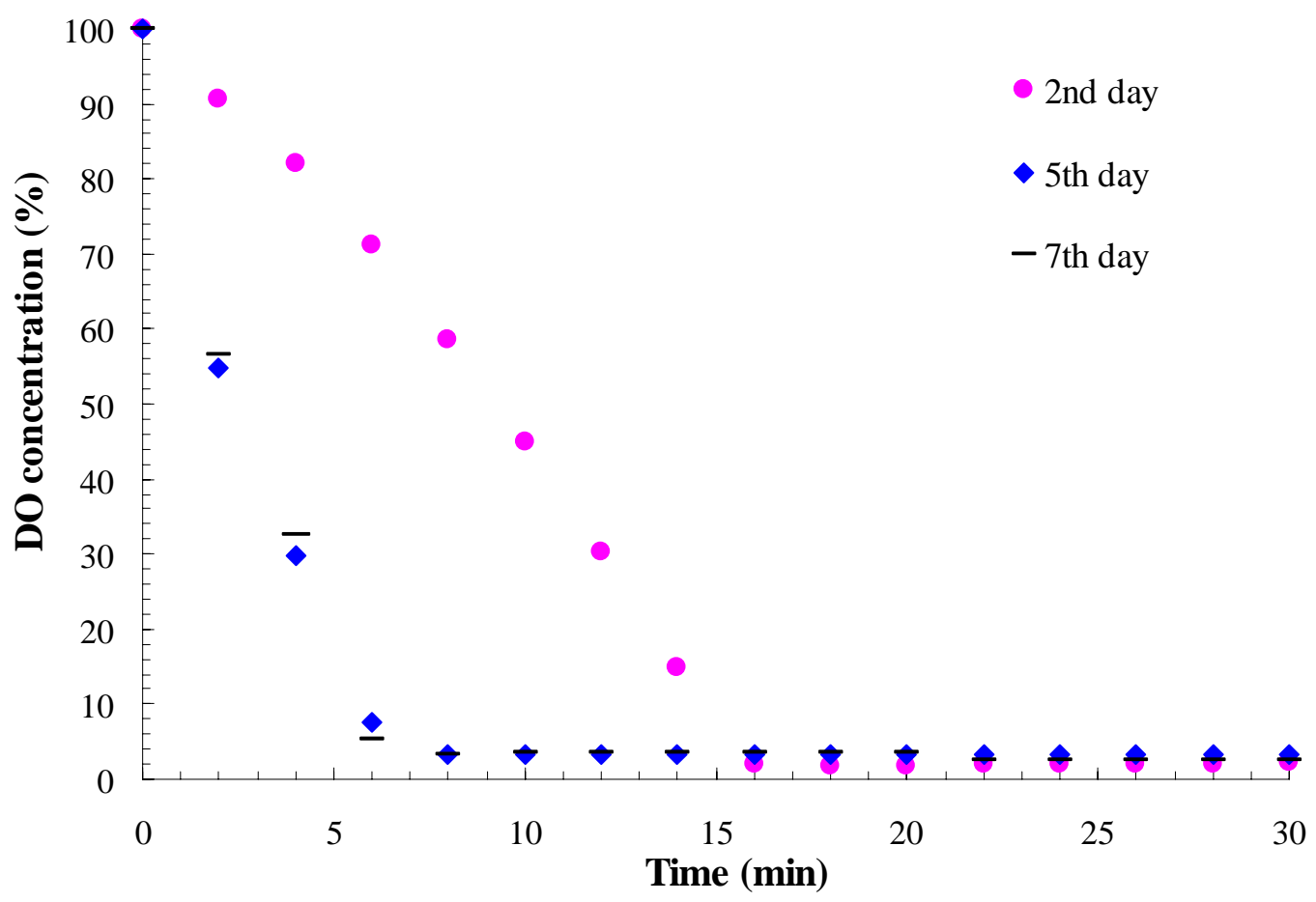

b) OUR variation of the mixed liquor in SMBR with MPE50

Figure 5. DO efficiency profile of SMBR+MPE50 (filtration flux $=30 \mathrm{~L} / \mathrm{m} 2 . \mathrm{h}$; MPE50 initial dose $=500 \mathrm{mg} / \mathrm{L}$ and daily addition of $80 \mathrm{mg} / \mathrm{L}$; backwash rate $=30 \mathrm{~L} / \mathrm{m}^{2} . \mathrm{h}$; backwash $=1$ minute every 0.5 hour)

\section{CONCLUSIONS}

SMBR with MPE addition significantly improved the sustainable flux and reduced the membrane fouling. The improvement was better than even the sponge SMBR system. 
SMBR with MPE achieved a high DOC (over 95\%) and COD removal efficiency (over 95\%) when running over 7-day period at a filtration flux of $30 \mathrm{~L} / \mathrm{m}^{2} . \mathrm{h}$. In addition, this system revealed outstanding $\mathrm{NH}_{4}-\mathrm{N}$ removal of over $95-98 \%$ and $\mathrm{PO}_{4}-\mathrm{P}$ removal of concentration of $62 \%$ which increased with time to over $99 \%$ after 7 days operation. In terms of phosphorus removal the sponge system performed better. OUR measurements showed that there was more microbial activity in the SMBR with MPE50 system

\section{ACKNOWLEDGEMENT}

This research was funded by DEST International Science Linkages Competitive Grant. The support of EUROMBRA is also acknowledged.

\section{REFERENCES}

[1] Stephenson, T., Judd, S. Jefferson, B. and Brindle, K. (2000). Membrane bioreactors for wastewater treatment. IWA Publishing, UK, 1 Jun 2000, ISBN: 1900222078.

[2] Guo, W. S., Vigneswaran, S., Ngo, H. H., Xing, W. and Goteti, P. (2007b). Comparison of the performance of submerged membrane bioreactor (SMBR) and submerged membrane adsorption bioreactor (SMABR). Bioresource Technology (in press, available online) 2007

[3] Guo, W. S., Vigneswaran, S., Ngo, H. H., Xing, W. (2007c). Comparison of membrane bioreactor systems in wastewater treatment. IWA Membranes Conference: Membranes for Water and Wastewater Treatment; Date: May 13-16, 2007, Harrowgate, UK

[4] Yoon, S.-H, Collins, J. H., Musale, D., Sundararajan, S. Tsai, S.-P., Hallsby, G. A., Kong, J. F. Koppes, J. and Cachia, P. Effects of flux enhancing polymer on the characteristics of sludge in membrane bioreactor process. Water Science \& Technology Vol 51 No 6-7 pp 151-157, 2005

[5] Lee, W., Kang, S., Shin, H., (2003). Sludge characteristics and their contribution to microfiltration in submerged membrane bioreactors. Journal of Membrane Science, 216, 217227.

[6] Field, R. W., Wu, D., Howell, J. A. and Gupta, B.B. (1995). Critical flux concept for microfiltration fouling. Journal of Membrane Science, 100, 259-272.

[7] Kwon, D.Y. and Vigneswaran, S., Fane, A.G. and Ben Aim, R. (2000). Experimental determination of critical flux in cross-flow microfiltration. Separation and Purification Technology, 19, 169-181.

[8] Li, H, Fane, A. G., Coster H. G. L., and Vigneswaran, S. (1998). Direct observation of particle deposition on the membrane surface during crossflow microfiltration. Journal of Membrane Science, 149, 1, 83-97.

[9] Bacchin, P., Aimar, P., and Field, R. W. (2006). "Critical and sustainable fluxes: Theory, experiments and applications." Journal of Membrane Science, 281(1-2), 42-69.

[10] Fane, T. and Leslie, G. (2004). Membrane technology - The key to water reuse. Proceedings of IWA Specialty Conference, Water Environment-Membrane Technology (WEMT2004), Seoul, Korea, 7-10 June, 875-883. 